\title{
Effect of carrier fill ratio on biofilm properties and performance of a hybrid fixed- film bioreactor treating coal gasification wastewater for the removal of COD, phenols and ammonia-nitrogen
}

\author{
E. Rava and E. Chirwa \\ E. Rava (corresponding author) E. Chirwa University of Pretoria,Water Utilisation Division, Pretoria 0002,South Africa \\ E-mail: emrava@buckman.com
}

\begin{abstract}
The purpose of this study was to determine the effect different biofilm carrier filling ratios would have on biofilm morphology and activity and bacterial diversity in a hybrid fixed-film bioreactor treating high strength coal gasification wastewater (CGWW) for the removal of chemical oxygen demand (COD), phenols and ammonia-nitrogen. Results showed that a carrier fill of 70\% formed a 'compact' biofilm, a 50\% fill formed a 'rippling' biofilm and a 30\% fill formed a 'porous' biofilm. The highest microbial activity was obtained with a 50\% carrier fill supporting a relatively thin biofilm. The highest level of biofilm bound metals were aluminium, silicon, calcium and iron in the 'compact' biofilm; nitrogen, magnesium, chloride, sodium and potassium in the 'rippling' biofilm, and copper in the 'porous' biofilm. The bioreactor improved the quality of the CGWW by removing $49 \%$ and $78 \%$ of the COD and phenols, respectively. However, no significant amount of ammonia-nitrogen was removed since nitrification did not take place due to heterotrophic bacteria out-competing autotrophic nitrifying bacteria in the biofilm. The dominant heterotrophic genera identified for all three carrier filling ratios were Thauera, Pseudaminobacter, Pseudomonas and Diaphorobacter.
\end{abstract}

Key words : Anox-Kaldness, biofilm, next-generation sequencing, nitrification, pollutants, Thauera

\section{Introduction}

Coal gasification wastewater (CGWW) is generated in the process of coal gas purification and contains large quantities of very complex organic and inorganic pollutants. Main pollutants in the wastewater are various phenolic compounds, poly-nuclear aromatic hydrocarbons, ammonia, thiocyanate, cyanide (Jia et al. 20I6), mono- and polycyclic nitrogencontaining aromatics, oxygen- and sulphur-containing heterocyclic compounds, sulphides, fatty acids and carbon dioxide (Gai et al. 2008). Thus, CGWW is considered to be very toxic, mutative, carcinogenic, teratogenic and may produce long-term adverse effects in the environment and on human health (Wang et al. 20I3). Phenols have been reported to be carcinogenic by the World Health Organization and a limit of $1 \mu \mathrm{g} / \mathrm{L}$ has been set to regulate phenol concentrations in drinking waters (Pishgar et al. 20I2).

There are intensive driving forces towards sustainable treatment and utilisation of wastewater. Reclamation of wastewater for recycling is growing rapidly and the demand for higher effluent quality is also increasing in a number of industries generating CGWW, such as the petrochemical, coking, iron and steel refineries. The treatment of CGWW can be sustainable if suitable technologies can be applied that operate using less energy, lower operating costs and lower investment (Ji et al. 20I5).

Biological treatment such as conventional activated sludge, sequencing batch reactor, and anoxic-aerobic and anaerobic-anoxic-aerobic processes, have been widely used to treat CGWW after being pre-treated by the processes of ammonia stripping and phenol solvent extraction to reduce the concentration of toxic compounds (Li \& Han 20I3). These biological processes have been shown to be more cost-effective, practical and highly reliable since there is minimal formation of toxic by-products and complete mineralisation of organic contaminants to water and carbon dioxide (Pishgar et al. 20I2). However, due to the 
presence of refractory and toxic compounds, the growth of nitrifying bacteria and specialised microbes in the aeration basin is restrained and/or these micro-organisms are washed out since they have low specific growth rates (Wang et al. 20I3). Thus, the formation of a biofilm on the carrier would prevent the nitrifiers being washed out of the bioreactor.

In biofilm processes, such as hybrid fixed-film bioreactors, the microbial biomass is attached as a film onto the surface of an inert and solid medium called the carrier. These carriers provide a large surface area for the growth of the micro-organisms. Removal of the contaminants is achieved when the CGWW is brought into contact with the biofilm (Pal \& Kumar 20I4). Biofilm processes have been proven to be one of the most effective and competitive alternatives for the treatment of high strength CGWW without the problems associated with conventional activated sludge processes, such as low process efficiency, poor sludge settle ability and unstable system performance (Zhou et al. 20I4). Hybrid fixed-film bioreactors have been shown to be more stable during fluctuating loading conditions and fixed micro-organisms are more resistant to changes in $\mathrm{pH}$, nutrients and toxic substances (Wang et al. 2013).

The main objective of this study was to evaluate the effect of different carrier media fill ratios on the biofilm morphology and activities and bacterial diversity as well as the removal of chemical oxygen demand (COD), phenols and ammonia-nitrogen using a pilot plant $(1,000 \mathrm{~L})$ situated at a refinery. The hybrid fixed-film bioreactor was fed continuously with real-time CGWW. It was hypothesised that the biofilm formed on the carriers would contain nitrifying bacteria for nitrification and the suspended biomass would contain heterotrophic bacteria for the removal of organic carbon (COD and phenols). The hybrid fixed-film bioreactor was operated at a relatively high oxygen concentration (5-6 mg/L) and the CGWW had a relatively high chemical oxygen demand/ammonium-nitrogen $\left(\mathrm{COD} / \mathrm{NH}_{4}-\mathrm{N}\right)$ ratio.

\section{Materials and methods}

\section{Pilot plant design and operating parameters}

A stainless steel hybrid fixed-film pilot bioreactor $(1,000 \mathrm{~L})$ with three in series aeration compartments (Zone 1, Zone 2 , and Zone 3) containing acclimatised biomass ( $>36$ months) was used in this study. The bioreactor was linked directly to a continuous real-time feed stream from the plant. The CGWW was diluted to 33\% to reduce the toxicity towards the biomass and to maintain an influent COD concentration around $2,000 \mathrm{mg} / \mathrm{L}$. Dilution was one part CGWW to two parts recycled sludge. The reactor was operated at $36^{\circ} \mathrm{C} \pm 1{ }^{\circ} \mathrm{C}$ and $\mathrm{pH}$ controlled at $7.5 \pm 0.5$. Polyethylene biofilm carrier (density $=0.95 \mathrm{~g} / \mathrm{mL}$ ) (AnoxKaldnes $^{\mathrm{TM}}$ K1, Veolia Water Technologies, Sweden) filling ratio (based on volume) for each aeration zone was approximately 70, 50 and 30\%, respectively. Food to mass ratio (kg COD/kg MLSS.d; MLSS: mixed liquor suspended solids) was maintained at $\leq 0.45$ of the biodegradable COD fraction, the organic loading rate was maintained at the design capacity of $\leq 3.5\left(\mathrm{~kg} \mathrm{COD} / \mathrm{m}^{3} . \mathrm{d}\right)$, sludge retention time was approximately 18 days and the hydraulic retention time was approximately $33 \mathrm{~h}$. The dissolved oxygen level was maintained between 5 and $6 \mathrm{mg} / \mathrm{L}$ using air diffusers fixed at the bottom of the respective aeration zones. Aeration also provided for hydraulic circulation. The clarifier up-flow velocity was controlled at $\leq 0.3 \mathrm{~m} / \mathrm{h}$.

\section{Biomass activity}

The oxygen uptake rate (OUR) of the biofilm was measured on-site using a Hach model HQ40d multimeter with an LDO 101 probe. A biochemical oxygen demand sample bottle $(300 \mathrm{~mL})$ was filled with $150 \mathrm{~mL}$ effluent and topped up with $150 \mathrm{~mL}$ AnoxKaldnes K1 carrier media taken from the respective zones, to simulate a 50\% media fill fraction (by volume) for comparative biofilm activities.

\section{Biomass weight}

The carriers (200 per aeration zone) were gently rinsed with water (3x), then dried at $105^{\circ} \mathrm{C}$ for $24 \mathrm{~h}$. The dried carriers were cooled in a desiccator before weighing. The attached biomass was then removed by soaking the carriers in $0.25 \mathrm{~N} \mathrm{NaOH}$ for $24 \mathrm{~h}$. The alkali wash was repeated with sonication for $90 \mathrm{~min}$. The carriers were then rinsed very well with water and dried for $24 \mathrm{~h}$ at $105^{\circ} \mathrm{C}$ and re-weighed. The difference in weight was used to determine the amount of biomass on the carriers.

\section{Biomass thickness and morphology}

For scanning electron microscopy (SEM), the carrier samples were allowed to air dry. Pieces of the biofilm were removed and mounted with adhesive carbon tape on aluminium stubs in the upright position. These were viewed in a Zeiss Ultra Plus field emission scanning electron microscope (FE-SEM) (Zeiss, Germany) at $10 \mathrm{kV}$. A point to point 
measurement was used to determine biofilm thickness using SmartSEM (Zeiss, Germany) software which was calibrated.

For scanning electron microscopy/energy-dispersive X-ray spectroscopy (SEM/EDX), the samples were mounted with adhesive carbon tape on aluminium stubs. These were viewed with a Zeiss Ultra Plus field emission gun-scanning electron microscope (Zeiss, Germany) at $20 \mathrm{kV}$. Images were digitally captured using the calibrated SmartSEM software (Zeiss, Germany). EDX analyses were performed using the AZtecEnergy) software (Oxford Instruments, UK) linked to an Oxford detector (Oxford Instruments, UK) with an $80 \mathrm{~mm}^{2}$ detection window. Imaging was performed using an in-lens detector for surface structure and an SE2 (Everhart-Thornley) detector for topography (Zeiss, Germany).

\section{Chemical analyses}

All samples were filtered through a $0.45 \mu \mathrm{m}$ filter before testing. Soluble COD, phenols, nitrates, nitrites and ammonianitrogen were determined using Standard Methods (APHA 20I2).

\section{High throughput Illumina next-generation sequencing}

Bacterial isolates were characterised by sequencing the $16 \mathrm{~S}$ rDNA using the ZR Fungal/Bacterial DNA MiniPrep ${ }^{\mathrm{TM}}$ test kit (Zymo Research Corp, USA). The universal primers 16S-27F (target 16S rDNA sequence ( $5^{\prime}$ to $3^{\prime}$ ) AGAGTTTGATCMTGGCTCAG) and 16S 1492R (target 16S rDNA sequence $\left(5^{\prime}\right.$ to $\left.3^{\prime}\right)$ CGGTTACCTTGTTACGATT) were used to amplify the $16 \mathrm{~S}$ target region using DreamTaq ${ }^{\mathrm{TM}}$ DNA polymerase (Thermo Scientific ${ }^{\mathrm{TM}}$, USA) and the primers were gel extracted using the Zymoclean ${ }^{\mathrm{TM}}$ Gel DNA Recovery Kit (Zymo Research, USA) and sequenced in the forward and reverse directions on the ABI PRISM 3500xl Genetic Analyser (Applied Biosystems ${ }^{\circledR}$, USA). For sequencing analyses, polymerase chain reaction products were purified using the ZR-96 DNA Sequencing Clean-up Kit ${ }^{\mathrm{TM}}$ and the purified products were analysed using the CLC Main Genomics Workbench v.7.0.3 bioinformatics software (CLCBio, Qiangen, Denmark) followed by a BLAST genome search on the most recent NCBI GenBank ${ }^{\circledR}$ database (http://blast.ncbi.nlm.nih.gov/Blast.cgi).

\section{Sampling}

Grab samples of the carriers and suspended biomass were taken from each zone on a weekly basis over a 6 month period and analysed on-site. Composite samples of the feed and effluent were taken on a daily basis, at a rate of $50 \mathrm{~mL} / \mathrm{h}$ over a $24 \mathrm{~h}$ period, and analysed on-site. Samples for biofilm studies and next-generation sequencing (NGS) analyses were chilled to $4{ }^{\circ} \mathrm{C}$ and transported in a coolerbox to the designated laboratory for analysis within $24 \mathrm{~h}$.

\section{Statistical analysis}

All samples for analysis were obtained at steady state conditions. Microsoft 7 Excel $^{\mathrm{TM}}$ was used to determine the average values, standard deviations and $P$-values. Significance level: $\alpha=0.05$. If $P \leq 0.05$, then difference was significant.

\section{Results and Discussion}

\section{Removal of phenols, COD and ammonia-nitrogen}

\section{Phenol removal}

The phenols in the feed ranged between 38 and $90 \mathrm{mg} / \mathrm{L}$ with an average of $70 \pm 20 \mathrm{mg} / \mathrm{L}$ and the phenols in the effluent ranged between 6 and $34 \mathrm{mg} / \mathrm{L}$ with an average of $15 \pm 8 \mathrm{mg} / \mathrm{L}$. The removal of phenols ranged between 62 and $93 \%$ with an average of $78 \pm 9 \%$.

\section{COD removal}

The COD in the feed ranged between 1,400 and 1,980 mg/L with an average of $1,750 \pm 170 \mathrm{mg} / \mathrm{L}$ and the COD in the effluent ranged between 480 and $1,170 \mathrm{mg} / \mathrm{L}$ with an average of $870 \pm 80 \mathrm{mg} / \mathrm{L}$. The removal of COD ranged between 37 and $62 \%$ with an average of $49 \pm 10 \%$.

\section{Ammonia-nitrogen removal}

The ammonia-nitrogen in the feed ranged between 166 and $684 \mathrm{mg} / \mathrm{L}$ with an average of $384 \pm 100 \mathrm{mg} / \mathrm{L}$ and the ammonia-nitrogen in the effluent ranged between 200 and $730 \mathrm{mg} / \mathrm{L}$ with an average of $377 \pm 95 \mathrm{mg} / \mathrm{L}$. The removal of ammonia-nitrogen ranged between 2 and 46\% with an average of $15 \pm 14 \%$. The reduction in ammonium-nitrogen was due to evaporative 'stripping' during aeration and not due to nitrification since there was no significant difference $(P \leq 0.05)$ between the average influent nitrate-nitrogen $\left(\mathrm{NO}_{3}-\mathrm{N}\right) \quad(5.61 \mathrm{mg} / \mathrm{L})$ and the average effluent $\mathrm{NO}_{3}-\mathrm{N}$ $(5.67 \mathrm{mg} / \mathrm{L})$. 


\section{Biofilm properties}

The OUR for Zone 1 was higher than in Zone 2 and Zone 3 (Table 1), However, the oxygen requirement in terms of biomass $\left(\mathrm{mg} \mathrm{O} \mathrm{O}_{2} / \mathrm{mm}^{2}\right.$ ) was $2.18,15.43$ and 2.66 for the respective zones, which implies the biofilm microbial consortium was more active in Zone 2 than in Zone 1 and Zone 3 . The oxygen requirement in terms of biofilm thickness $\left(\mathrm{mg} \mathrm{O}_{2} / \mu \mathrm{m}\right)$ was $1.22,5.46$ and 5.03, respectively which implies the biofilm microbial consortium was more active in 'thinner' biofilms (Zone 2 and Zone 3) than in thicker biofilms (Zone 1). This was due to the higher number of active cells in relation to the biofilm extracellular polymeric substance (EPS) (Andersson 2009).

The biofilm of Zone 1 differed significantly $(P \leq 0.05)$ from Zone 2 and Zone 3. The biofilm in Zone 1 was thicker than in Zone 2 and Zone 3 due to the higher COD loading rate (Karizmeh et al. 2014). Higher electrolyte (conductivity, osmolarity) and nutrient concentrations promote deeper substrate penetration into the biofilm as well as greater cell reproduction and thus thicker biofilm (Gerardi 2002). The biomass volume in Zone 1 was higher than in Zone 2

Table 1 | Biofilm properties measured at different carrier filling ratios

\begin{tabular}{llll} 
Parameters measured & Zone 1 & Zone 2 & Zone 3 \\
\hline Biomass carrier filling ratio $(\%)$ & 70 & 50 & 30 \\
OUR $\left(\mathrm{mg} \mathrm{O}{ }_{2} / \mathrm{L} \cdot \mathrm{h}\right)$ & 62.6 & 33.8 & 33.7 \\
Average biofilm thickness $(\mu \mathrm{m})$ & 51.5 & 6.19 & 6.61 \\
Average biomass $\left(\mathrm{mg} / \mathrm{mm}^{2}\right)$ dry basis & 29.8 & 2.19 & 6.89 \\
\hline
\end{tabular}

and Zone 3. Shear stresses on the biofilm surface will also affect biofilm thickness and structure.

\section{Biofilm morphology and effect of metals and ions}

\section{Biofilm morphology}

SEM analyses indicated the biofilm morphology to be relatively 'compact' for Zone 1 (Figure 1), 'rippling' for Zone 2 (Figure 2) and 'porous' for Zone 3 (Figure 3). EDX analyses of the biofilm layers indicated the presence of carbon, oxygen, sodium, magnesium, aluminium, silicon, phosphorus, sulphur, chloride, potassium, calcium, nitrogen, copper and iron in all three aeration zones. The levels of carbon, oxygen, phosphorus and sulphur present in the biofilm layers were very similar. Levels of aluminium, silicon, calcium and iron were highest in Zone 1 with nitrogen, magnesium, chloride, sodium and potassium highest in Zone 2, and, copper highest in Zone 3. Therefore, the cell clusters, interstitial voids and channels, and the mass transfer properties of nutrients will differ between the respective biofilms (Picioreanu et al. 200I).

\section{Effect of metals and ions on biofilm morphology}

EPS are anionic and act as an ion exchange resin where divalent bridges can be formed or broken due to relative concentrations of monovalent and divalent cations competing for negative sites. The presence of divalent cations influences biofilm formation directly through its effect on electrostatic interactions, and indirectly via physiologically

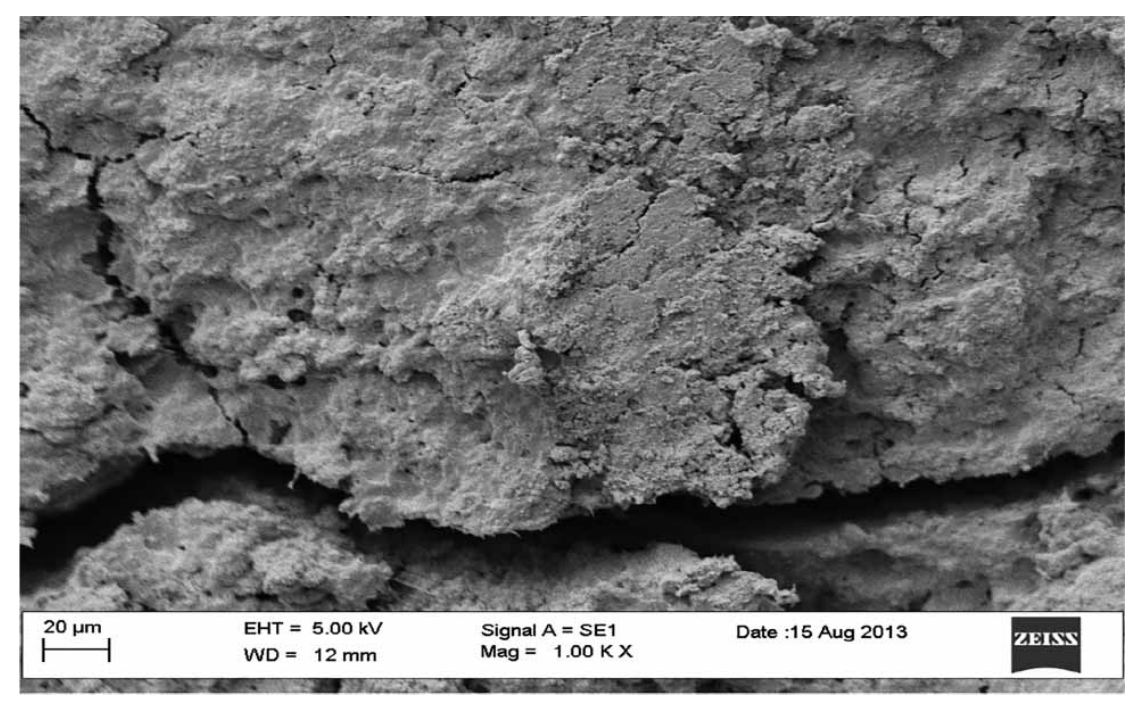

Figure 1 | Scanning electron microscopy of the biofilm in Aeration Zone 1. 


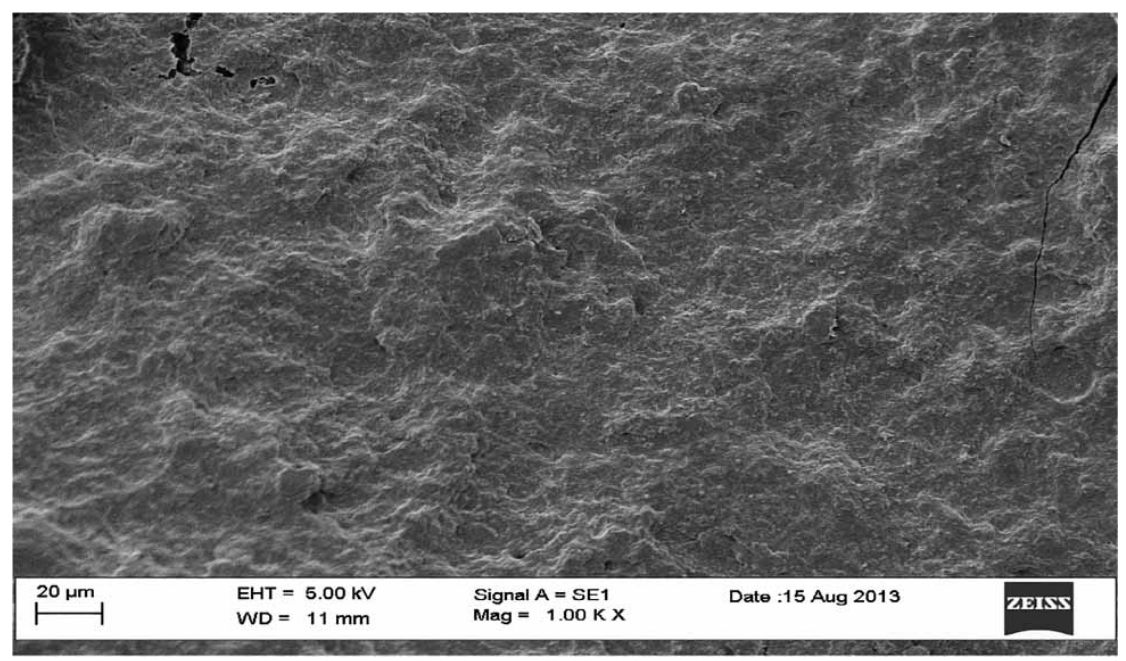

Figure 2 | Scanning electron microscopy of the biofilm in Aeration Zone 2.

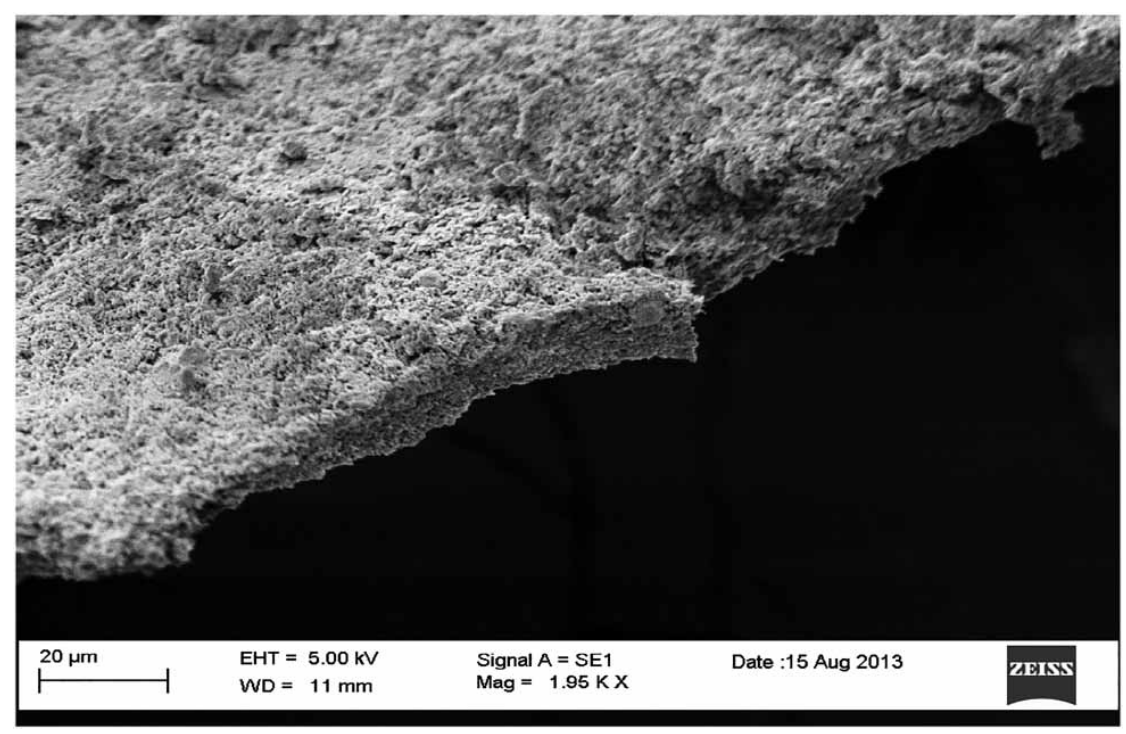

Figure 3 | Scanning electron microscopy of the biofilm in Aeration Zone 3.

dependent attachment processes by acting as cellular cations and enzyme cofactors (Song \& Leff 2006; Todar 2006). Calcium and phosphorus absorb and accumulate in the biofilm as insoluble compounds, rendering the biofilm highly resistant to detachment. Calcium ions act as crosslinkers and make the EPS more proteinaceous (thinner) (Revanuru \& Mishra 20II). Sulphur is required for protein synthesis, phosphorus for nucleic acids and metabolic cofactors, and nitrogen for proteins, some sugars and nucleic acids. Silicon and aluminium increase biofilm resistance to toxic shocks, and the presence of iron and sulphur contribute to the aggregation of biomass. Potassium, magnesium, sodium, calcium, iron and chlorides are macronutrients required for membrane stabilisation (Hu et al. 20I3).

\section{Nitrification and bacterial identifications}

\section{Nitrification bacteria}

Autotrophic bacteria (family of Nitrobacteraceae) such as ammonia-oxidising bacteria (AOB) (Nitrosomonas, Nitrosospira, Nitrosococcus) and nitrite-oxidising bacteria (NOB) (Nitrospira, Nitrobacter, Nitrospina) are required for nitrification to take place (Andersson 2009). Zhang 
et al. (320I) reported Nitrosomonas to be dominant in high ammonia environments, Nitrosospira to be dominant in low ammonia environments, Nitrobacter to be dominant in high substrate availability conditions and Nitrospira to be dominant during starved conditions. Optimal temperature for AOB ranges between $30^{\circ} \mathrm{C}$ and $35^{\circ} \mathrm{C}$, and $35^{\circ} \mathrm{C}$ t o $40^{\circ} \mathrm{C}$ for NOB (Shore et al. 20I2). This indicates that Nitro-somonas and Nitrobacter should be present within the deeper sections of the biofilm formed on the carriers.

\section{Bacterial identifications (biofilm)}

NGS indicated that the dominant kingdom classification for all the biofilms was Bacteria. The dominant phyla were Proteobacteria, Firmicutes and Bacteriodetes. These phyla were also reported by Meng et al. (520I) as being present in coking wastewater. The dominant classes were Beta-proteobacteria, Alpha-proteobacteria, Gamma-proteobacteria; the dominant orders were Rhizobiales, Rhodocyclales and Burkholeriales; the dominant families were Rhodocyclaceae, Alcaligenaceae and Phyllobacteriaceae. The closest genera and species match hits, using the BLASTN genome ( $\geq 99 \%$ homology) search on the most recent NCBI GenBank ${ }^{\circledR}$ database (http://blast.ncbi.nlm.nih.gov/Blast.cgi), were Thauera butanivorans (NR_040797.1), Pseudaminobacter salicyclatoxidans (NR_028710.1), Pseudomonas aeruginosa (AF440523) and Diaphorobacter nitroreducens (AB07856.1). The biofilm morphology and activity for each aeration zone differed; however, the population remained fairly simi-lar. No autotrophic nitrifying bacteria developed in the deep dense sections of the respective biofilms. The biofilms can thus be regarded as consisting of heterotrophic bacteria possibly having nitrification capabilities under ideal bioreactor conditions since Ge et al. (520I) reported

Diaphorobacter sp. PD-7 strain as being capable of phenol degradation, heterotrophic nitrification and aerobic denitrification in activated sludge from a coking wastewater plant.

\section{Conclusions}

The main conclusions are as follows:

- Bioreactor hydrodynamics and biofilm characteristics such as activity, density, diversity and structure affected the performance of a hybrid fixed-film bioreactor. Thus, control of the biofilm structure is an important requirement for stable bioreactor performance since the biofilm controls the rate of mass transfer of nutrients and substrate to the microbial community within the biofilm (autotrophic nitrifiers) and on the surface of the biofilm (heterotrophs).

- Nitrification and carbon removal did not take place under high oxygen concentration since the autotrophic nitrifying bacteria in the heterogeneous biofilm were out-competed by the heterotrophic bacteria. The biofilm thickness was not sufficient (thin) to support autotrophic nitrifiers. However, the biofilm did support possible het-erotrophic nitrifying bacteria.

- The use of a culture-independent method such as highthroughput Illumina NGS allowed for the identification of bacteria that would not have been isolated/identified using traditional culturing methods.

\section{Acknowledgments}

The authors would like to thank Buckman Africa for funding the chemical, EDX and SEM analyses, University of Pretoria for funding the next-generation sequencing and Sasol Technology (Pty) Ltd for the use and operation of the pilot plant. The authors declare no financial interests exist.

\section{References}

Andersson, S. gooCharacterization of Bacterial Biofilms for Wastewater Treatment. Royal Institute of Technology, Universitetsservice US-AB, Stockholm, Sweden.

APHA 2102Standard Methods for the Examination of Water and Wastewater, 22nd edn. American Public Health Association/American Water Works Association/Water Environment Federation, Washington, DC.

Gai, H., Jiang, Y., Qian, Y. \& Kraslawski, A. 8002Conceptual design and retrofitting of the coal-gasification wastewater treatment process. Chemical Engineering Journal 138, 84 -

94. Ge, Q., Yue, X. \& Wang, G. 5IO2Simultaneous heterotrophic nitrification and aerobic denitrification at high initial phenol concentration by isolated bacterium Diaphorobacter sp. PD-7. Chinese Journal of Chemical Engineering 23 (5), 835-841.

Gerardi, M. 2002Nitrification and Denitrification in the Activated Sludge Process. Wiley, New York.

Hu, X. B., Wang, Z., Ding, L. L. \& Ren, H. Q. 3102Characteristics of biofilm attaching to carriers in moving bed biofilm reactor used to treat vitamin C wastewater. Scanning 35 (5), 283-291.

Ji, Q., Tabassum, S., Yu, G., Chu, C. \& Zhang, Z. 5IO2A high efficiency biological system for treatment of coal gasification wastewater-key depth technology research. RSC Advances 5 (50), 40402-40413. 
Jia, S., Han, H., Zhuang, H. \& Hou, B. 6102The pollutants removal and bacterial community dynamics relationship within a full-scale British Gas/Lurgi coal gasification wastewater treatment using a novel system. Bioresource Technology 200, 103-110.

Karizmeh, M., Deltolla, R. \& Narbaitz, R. 4IO2Investigation of settleability of biologically produced solids and biofilm morphology in moving bed biofilm reactors (MBBRs). Bioprocess and Biosystems Engineering 37 (9), 1839-1848.

Li, H. \& Han, H. 3102Effect of recycle ration on performance of pre-denitrification moving bed biofilm reactors in treating coal gasification wastewater. Desalination and Water Treatment 52 (37-39), 6894-6903.

Meng, X., Li, H., Sheng, Y., Cao, H. \& Zhang, Y. 5IO2Analysis of

a diverse bacterial community and degradation of organic compounds in a process for coking wastewater. Desalination and Water Treatment DOI: 10.1080/19443994.2015. 1100556.

Pal, R. \& Kumar, R. 4IO2Treatment of coke wastewater: a critical review for developing sustainable management strategies. Separation and Purification Technology 43, 8 9-123.

Picioreanu, C., van Loosdrecht, M. C. \& Heijnen, J. J. 20oITwodimensional model of biofilm detachment caused by internal stress from liquid flow. Biotechnology Resources 72 (2), 205218.

Pishgar, R., Najafpour, G. D., Mousavi, N., Bakhshi, Z. \& Khorrami, M. 2IO2Phenol biodegradation kinetics in the presence of supplementary substrate. International Journal of Engineering Transaction B: Applications 25, 181-191.
Revanuru, S. \& Mishra, I. M. II02Chemical characteristics of the granular sludge from an UASB reactor treating binary mixture of catechol and resorcinol in an aqueous solution. In: Proceedings of 2nd International Conference on Environmental Engineering and Applications - ICEEA 2011, August 19-21, Shanghai, China, pp. 128-133.

Shore, J. L., McCoy, W. S., Gunsch, C. K. \& Deshusses, M. A. 2IO

2 Application of a moving bed biofilm reactor for tertiary ammonia treatment in high temperature industrial wastewater. Bioresource Technology 112, 5 1 -60.

Song, B. \& Leff, L. G. 2006Influence of magnesium ions on biofilm formation by Pseudomonas fluorescens. Microbiology Research 161, 355-361.

Todar, K. 6002Todar's Online Textbook of Bacteriology. Department of Bacteriology, University of Wisconsin-Madison, Madison, USA.

Wang, Z., Xu, X., Chen, J. \& Yang, F. 3IO2Treatment of Lurgi

coal gasification wastewater in pre-nitrification anaerobic and aerobic biofilm process. Journal of Environmental Chemical Engineering 1, 899-905.

Zhang, S., Wang, Y., He, W., Wu, M., Xing, M., Yang, J., Gao, N. \& Yin, D. 320IResponses of biofilm characteristics to variations in temperature and $\mathrm{NH} 4(+)-\mathrm{N}$ loading in a moving-bed biofilm reactor treating micro-polluted raw water. Bioresource Technology 131, 355-375.

Zhou, X., Li, Y. \& Zhao, Y. 4102Removal characteristics

of organics and nitrogen in a novel four-stage integrated system for enhanced treatment of coking wastewater under different HRTs. Research Advances 4, 15620-15629. 